\title{
Designing a deprivation payment for general practitioners: the UPA(8) wonderland
}

\author{
Roy A Carr-Hill, Trevor Sheldon
}

TABLE I-Deprivation payment to general practitioners from April to 31 December 1990

\begin{tabular}{lcc}
\hline & $\begin{array}{c}\text { Index } \\
\text { score }\end{array}$ & $\begin{array}{c}\text { Payment per } \\
\text { patient per } \\
\text { year }(\mathfrak{\Sigma})\end{array}$ \\
\hline Lower & $30-39.99$ & 4.90 \\
Middle & $40-49.99$ & 6.40 \\
Higher & $50-59.99$ & 8.50 \\
\hline
\end{tabular}

Centre for Health

Economics, University of York, York YO1 5DD Roy A Carr-Hill, DPHIL, senior research fellow

Department of Public Health Medicine, University of Leeds Trevor Sheldon, MSC, lecturer

Correspondence to: Dr Carr-Hill.

BMF 1991;302:393-6

\section{Abstract}

Objective-To analyse critically the deprived area payment introduced in the new general practitioner contract. The payment formula is based on the Jarman underprivileged area index (UPA(8)) and aims at compensating general practitioners for increases in workload.

Design-Evaluation of the deprived area payment against the stated policy objective with a set of criteria for developing resource allocation formulas.

Main outcome measures - The degree to which the components of the Jarman index predict the workload of general practitioners; whether construction of the index is sensible and comprehensible; and how the formula incorporates the index and is likely to work in practice.

Results - The fact that the index relies on census data and the way the weighting was derived means that the formula will not accurately reflect the workload. The use of statistical transformations obscures the original policy intent. There has been no validation to support the application of the index as part of a national policy. The payments are not linked to the quality of service provided and may have the perverse effect of increasing list size.

Conclusion-The formula used as the basis of the deprived area payments is poorly suited to the policy objective of compensating general practitioners for increases in workload. More research is urgently needed to enable the effect of the payment to be monitored and a more empirically sound set of incentives to be developed.

\section{Introduction}

The new contract for general practitioners makes provision for a "deprivation payment." This is based on a formula whereby an additional sum (table I) is paid for each person on the list who lives in an area with a score on the Jarman underprivileged area index (UPA(8)) that falls in the top $5 \%$ of the national distribution. Only 454 wards out of the 8465 wards in England qualify.

The presumption since the foundation of the NHS has been that it is difficult to persuade doctors to work in poor socially deprived areas. ${ }^{2}$ The conventional wisdom accepted among doctors and many researchers is that the work is more stressful if not time consuming in areas of social deprivation so that some incentives are required. ${ }^{3}$

Before the new contract, in force since April 1990, about $30 \%$ of general practitioners' income came from the basic practice allowance and about $45 \%$ from capitation; apart from these payments, a wide range of fees for items of service and other subsidies only marginally discriminated against doctors with patients predominantly from poorer areas. In fact, there were few clear incentives in the previous system, ${ }^{4}$ although entry into general practice was easier in designated $\vec{c}$ areas. Now that $55-60 \%$ of income (on average) comes from capitation - thereby giving general practitioners the incentive to select larger lists-and threshold payments are available for meeting screening targets $N$ that will be difficult in deprived areas, ${ }^{5}$ pressure for another kind of incentive to work in such areas has been generated.

Argument about the impact of this scheme in $\omega$ practice abounds. In this paper we ask two funda- 은 mental questions: How should a formula for compen- $\vec{\sigma}$ sating general practitioners for a heavier workload be constructed? and, Is the Jarman index the correct basis for that formula?

\section{Constructing a formula for resource allocation}

Innes and Stoddard recommended a set of ground rules for developing a formula for the allocation of resources ${ }^{6}$ :

- Definitions of policy intent should be distinct from the formulas themselves

- The components of formulas should relate to the phenomenon rather than simply be conveniently measured factors

- The construction of a formula should be clear and comprehensible to users and to the public

- How a formula is working in practice should be regularly evaluated.

These criteria provide a useful framework for assessing the acceptability of a formula while recognising that the development of such a formula not only is a technical process but has a political dimension.

\section{Setting the policy objective}

The first step is to specify the policy objective $N$ precisely. Whereas the name of the payment and the basic data for implementing the formula refer to deprivation and to deprived areas respectively, the 0 purpose of the payment is to compensate for a presumed increase in and difficulty of workload and not to provide extra health care to deprived areas. ${ }^{7}$ The intention is therefore that a general practitioner can reach the same income target with a shorter list of patients who generate more work. Whether the index is a good measure of deprivation and whether health care expenditure is effectively used to compensate for deprivation itself are entirely separate issues.

There are doubts about which of the many service and social factors contribute to extra workload, particularly whether the workload of general practitioners in deprived areas (however defined) is actually heavier than that of those elsewhere. ${ }^{8}$ The choice of formula is thus very important. 


\section{Is the Jarman index appropriate?}

The second step is to search for a formula that will correspond to the policy intent. If the intensity of a general practitioner's workload were thought to depend on the social class of the patients, for example, the social class of each patient would need to be known. Another approach might be to suggest that general practitioners' workload depends on the environmental conditions within which they have to work, so that the crucial index would be related to the (main) surgery address. The new contract does not take either of these positions: instead the implicit assumption behind the deprivation payment in the new contract is that a practice's workload depends on the environmental characteristics of the patients on the list. Therefore, though superficially a patient based measure, the payment depends on environmental information: an unhappy and not altogether meaningful mix of bases.

Nevertheless, the index chosen - the Jarman underprivileged area index ${ }^{9}$ - was developed to measure the workload of the general practitioners in terms of the residential deprivation of their patients and therefore seems to be highly appropriate once it has been decided that extra payments should depend on the environmental background of the patients. A list of relevant variables was constructed from a few hundred replies to a survey of London general practitioners and related organisations; then a national $10 \%$ sample of general practitioners was asked to score 21 service and social factors from 0 to 9 according to the degree to which each one increased workload or contributed to the pressure of work. Jarman excluded the service factors and he used the average scores they gave on eight of the social variables as weights (table II). The score was constructed as "the sum of the weighted values of each variable after the variable was transformed and standardised," $"$ and at the ward level ranges from about -50 (most privileged) to about 50 (most underprivileged).

The index has validity on face value because its components are based on responses by general practitioners about the kind of factors that might affect their workload. There are, however, several difficulties.

\section{RELIANCE ON CENSUS DATA}

Firstly, the Jarman index relies on data from the 1981 census, which has two shortcomings.

Circumstances may have changed since 1981, yet few of the component variables can be updated until 1993, when the 1991 census data become available. At that point a large shift in the value of the index and consequently payments to general practitioners might be expected given the results of the Welsh district health authorities 1986 intercensal survey. ${ }^{11}$ The values of the Jarman index (which vary less than for wards because of averaging) ranged from -0.80 to 10.74 in 1981 (table III). The change in the index due to just two of the component variables in 1986-the proportions of unskilled and unemployed people - was substantial (around 20\%) and led to a change in ranks.

TABLE III - Variability in values of components of Farman scores in Welsh health districts in 1981 and $1986^{1112}$

\begin{tabular}{|c|c|c|c|c|c|c|}
\hline & \multicolumn{2}{|c|}{ Unskilled people } & \multicolumn{2}{|c|}{ Unemployed people } & \multicolumn{2}{|c|}{ Jarman score } \\
\hline & 1981 & 1986 & 1981 & 1986 & 1981 & $\begin{array}{c}\text { Change in } \\
1986\end{array}$ \\
\hline Clwyd & 4.9 & $5 \cdot 5$ & $13 \cdot 4$ & $9 \cdot 6$ & $8 \cdot 26$ & -1.98 \\
\hline Dyfed & $4 \cdot 2$ & $4 \cdot 5$ & $11 \cdot 3$ & $9 \cdot 8$ & $3 \cdot 24$ & -0.73 \\
\hline Gwent & $6 \cdot 3$ & $6 \cdot 3$ & $14 \cdot 0$ & $10 \cdot 4$ & $6 \cdot 85$ & $-2 \cdot 35$ \\
\hline Gwynedd & $5 \cdot 7$ & $5 \cdot 2$ & $12 \cdot 6$ & $10 \cdot 5$ & $10 \cdot 74$ & -1.86 \\
\hline Mid Glamorgan & $5 \cdot 2$ & $6 \cdot 6$ & $15 \cdot 0$ & $10 \cdot 8$ & $6 \cdot 27$ & -1.48 \\
\hline Powys & $3 \cdot 9$ & $3 \cdot 9$ & $7 \cdot 9$ & $6 \cdot 1$ & $-0 \cdot 80$ & -1.50 \\
\hline South Glamorgan & $4 \cdot 6$ & $4 \cdot 7$ & $11 \cdot 7$ & $9 \cdot 1$ & $9 \cdot 26$ & $-1 \cdot 72$ \\
\hline West Glamorgan & $6 \cdot 2$ & $6 \cdot 5$ & $14 \cdot 1$ & $11 \cdot 7$ & $5 \cdot 86$ & $-1 \cdot 27$ \\
\hline
\end{tabular}

Changes in wards are likely to be much larger, leading to substantial shifts in the allocation of payments.

Only a few questions are asked in the census and the measures most appropriate for indexing workload are unlikely to be found among this small set. Obvious exclusions are service factors, although these were explicitly left out by Jarman. ${ }^{9}$

Both of these criticisms would apply to any index based on census data such as the Department of the Environment index, the classification of residential neighbourhood index, and the Townsend index. ${ }^{13}$

\section{DERIVING WEIGHTS}

Secondly, how the weights of the social factors of the Jarman index were derived needs to be considered.

The general practitioners were asked to score the eight social factors from 0 to 9 . The instructions were:

"Below is a list of factors which evidence suggests contribute to the pressure of work on General Practitioners. Based on experience in your practice, could you please score each factor on a scale from 0 (no problem) to 9 (very problematical) according to the degree to which it increases workload or contributes to the pressure of work when it is present...."Without any clear guidance, problematical will mean different things to different people. In addition, some general practitioners may have treated the scale as linear, some as quadratic; many may have answered the question as if it were an implicit ranking exercise. Without a reasonable presumption of a common scale, it is difficult to have any confidence in a parametric index.

The general practitioners were also asked to evaluate the extent to which the factors resulted in a heavier workload. They could assess this only on the basis of the patients they saw. But general practitioners have no way of knowing whether patients on their list with the given characteristics consult more than would be expected given their proportion on the list. If, for example, $15 \%$ of a general practitioner's load is generated by single parents his or her impression will be that being a single parent is an important factor. After adjustment for age (which affects capitation fees), however, single parents might make up about $15 \%$ of the list and in fact not be making a disproportionate demand.

In addition, some people consulting their doctor may be noted simply because of one of the crucial eight characteristics. A general practitioner may, for example, particularly remember those from an ethnic minority, old people living alone, or single parents, so gaining the impression that they constitute a larger proportion of his workload than is the case.

Finally, general practitioners were asked their opinion about the characteristics of households and people and their demands on primary care from the point of view of their list. They could not make and were not making judgments about variations between lists or between electoral wards or between districts. But the Jarman index is used as a ward based measure.

\section{Constructing a comprehensible formula}

In the third step an index needs to be understandable to be useful. This is not the case with the Jarman index.

\section{OBSESSION WITH NORMALITY}

The transformation (the inverse of the trigonometric sine of the square root of the proportion) is not justified except for reasons of statistical convention - that is, it is intended to make the distribution of the scores normal. But there is no evidence to suggest that pressure of workload on general practitioners is normally distributed: Jarman has simply assumed it.

This transformation has a noticeable effect when the values of the index are compared across time. Consider 


\begin{tabular}{lcc}
\hline & & \\
$\mathbf{x}$ & Arc sine $\mathrm{x}$ & $\begin{array}{c}\text { Change } \\
\text { in value }\end{array}$ \\
\hline 0.00 & 0.000 & \\
0.05 & 0.226 & 0.226 \\
0.10 & 0.322 & 0.096 \\
0.15 & 0.398 & 0.076 \\
0.20 & 0.464 & 0.066 \\
0.25 & 0.524 & 0.060 \\
0.30 & 0.580 & 0.056 \\
0.35 & 0.633 & 0.053 \\
0.40 & 0.685 & 0.052 \\
0.45 & 0.735 & 0.050 \\
0.50 & 0.785 & 0.050 \\
\hline
\end{tabular}

two areas, one comparatively fortunate with an unemployment rate of $5 \%$, the other comparatively deprived, with a rate of $15 \%$. Suppose that there is an upwards shift of $5 \%$ across the country. Then, because of the nature of the transformation, the contribution of unemployment to the Jarman index for the comparatively fortunate area will increase by nearly $50 \%$ more than that for the comparatively deprived area (table IV).

\section{WEIGHTING TRANSFORMED SCORES}

The weighting of the component transformed scores is not sensible.

Firstly, however the general practitioners interpreted the instructions for scoring the factors they certainly did not envisage the scores they gave being applied to the transformed variables.

Secondly, the transformed variables were standardised. This implicitly weights the variable by the inverse of its variability. There is no obvious reason for this (implied) weighting and it makes the index less clear.

Thirdly, there is a considerable element of double counting. Irving and Rice, who did much of the statistical work on the Jarman index, and Jarman acknowledged that there were intercorrelations between the eight variables but ignored the effect of this on the index..$^{145}$ Not only are the intercorrelations high ${ }^{14}$ but the correlations between the transformed variables are even higher (table V). Of the 28 correlation coefficients, 11 are above 0.3 . The intercorrelations between the transformed values of the proportions of single parents, of unskilled people, of unemployed people, and of people living in overcrowded conditions are particularly high at around 0.5 , implying a common variance of $25 \%$. They should have been taken account of when constructing the index. ${ }^{16}$

\section{Does the index work?}

The fourth step is to assess the validity of the index as a measure of workload and its potential effect as a basis of differentiated capitation payments.

\section{VALIDITY}

In an attempt to validate the UPA(8) index Jarman asked local medical committees in family practitioner committee areas to indicate the worst and the intermediate wards. ${ }^{15} \mathrm{He}$ concluded that, at most, only 26 assignments out of 413 were different $(6 \cdot 3 \%)$. This exercise establishes, at most, consensus validity in that there is general agreement in the local rankings given by the index score and the local medical committees. This in no way, however, validates the index as a measure of workload. Moreover, the fact that the cut off points for the worst areas depended on local perceptions and were not the same between areas ${ }^{15}$ means that this exercise does not provide a validation for the use of the Jarman index as the basis of a national policy.

Thus, it is not surprising that the bulk of the debate about the payment has been about the applicability of the index in different parts of the country. As a result of lobbying, the payment in both Wales and Northern Ireland is based on an amended set of variables, which raises even more questions about the scientific basis of the formula. It is equally unscientific to simply lower the cut. off point by using some arbitrary notion of when health deprivation starts ${ }^{3}$ or by reference to statistical convention. ${ }^{17}$

Leavey and Wood compared the value of the Jarman index with objective indicators of general practitioners' workload in Manchester, Salford, and Trafford. ${ }^{18}$ They found that doctors living in the worst wards (according to the index) had the highest doctor-patient ratios and were rationing their workload by spending less time on average with their patients, compared with general practitioners with surgeries in the best wards.

Charlton and Lakhani tried to validate the score by seeing whether it correlated well with higher mortality from causes that can be reduced substantially by the intervention of general practitioners. ${ }^{19}$ Though this may illustrate the relation between the Jarman score and some crude measure of need, it is not a validation of the Jarman index as a measure of workload.

The only study to date that sheds any light on the validity of the Jarman index as a measure of workload is reported by Curtis on the basis of a household survey in three London districts. ${ }^{20}$ She found a correlation between the Jarman index for the enumeration district where the respondent lived and responders' self reported morbidity and, separately, their rate of consultation with general practitioners. There are some doubts, however, about the presentation of the results and the statistical analysis. The model she constructs shows some relation between the consultation rate and the Jarman score but she does not test whether this is equally well explained by socioeconomic characteristics of individual patients (such as social class) rather than being dependent on an area index. Moreover, there is no way of assessing the extent to which differences in the consultation rate are accounted for by the Jarman index.

\section{OPERATION OF PAYMENT}

The proposal presumes that there are threshold levels that define bands within which variations in the environmental conditions make no difference to general practitioners' workload but that patients either side of these thresholds are qualitatively different. No evidence is presented for this presumption and it does not seem very plausible.

Moreover, the deprivation payment is an addition to the structure of capitation payments. The Jarman index includes a weighting for areas with more elderly people living alone, but general practitioners already receive a higher capitation payment for someone aged over 65 (from April to December $1990 £ 11.95$ for patients $<65, £ 15.75$ for those aged $65-75, £ 30.75$ for those $>75$ ). If the argument were that the present capitation payment for patients over 65 were judged insufficient then it should be augmented rather than include an additional payment for only some general practitioners.

Most importantly, the extra financial rewards, which for a single general practitioner may be over

TABLE $\mathrm{V}-$ Intercorrelations between standardised transformed component variables of farman underprivileged area index in 9289 wards in England and Wales (based on 1981 census data)

\begin{tabular}{|c|c|c|c|c|c|c|c|}
\hline & $\begin{array}{l}\text { Children } \\
<5 \text { years }\end{array}$ & $\begin{array}{l}\text { Single parent } \\
\text { household }\end{array}$ & $\begin{array}{l}\text { Unskilled } \\
\text { people }\end{array}$ & $\begin{array}{l}\text { Unemployed } \\
\text { people }\end{array}$ & $\begin{array}{l}\text { Overcrowded } \\
\text { households }\end{array}$ & $\begin{array}{l}\text { People who have } \\
\text { moved house }\end{array}$ & $\begin{array}{l}\text { Ethnic minority } \\
\text { households }\end{array}$ \\
\hline Old people living alone & 0.42 & $0 \cdot 11$ & $0 \cdot 17$ & $0 \cdot 24$ & 0.06 & $0 \cdot 11$ & 0.07 \\
\hline Children $<5$ years & & 0.35 & $0 \cdot 20$ & $0 \cdot 20$ & $0 \cdot 32$ & $0 \cdot 25$ & $0 \cdot 19$ \\
\hline Single parent households & & & 0.46 & 0.56 & 0.58 & $0 \cdot 18$ & $0 \cdot 36$ \\
\hline Unskilled people & & & & 0.57 & 0.54 & 0.01 & $0 \cdot 19$ \\
\hline Unemployed people & & & & & 0.68 & 0.07 & $0 \cdot 20$ \\
\hline Overcrowded households & & & & & & $0 \cdot 10$ & 0.55 \\
\hline People who have moved house & & & & & & & $0 \cdot 26$ \\
\hline
\end{tabular}


$£ 10000$ a year, are not linked to the amount of work done let alone to the quality of service provided by the practice. Under certain circumstances this may generate perverse incentives, contrary to policy intent. Indeed, the marginal cash benefit to the general practitioner of a person in the list will be the extra capitation, which is higher for people from deprived areas (table I). The marginal cost of taking on that person is the extra work generated, but as general practitioners can ration the work they do by reducing office hours and other routes by which patients obtain access, this could lead to some (less committed) general practitioners in deprived areas who are income maximisers increasing rather than decreasing their list size. ${ }^{21}$

\section{Conclusion}

We emphasise that, despite the name and the common (but incorrect) use of the Jarman index in other contexts as a measure of deprivation - for example, in the Resource Allocation Working Party (RAWP) review - the intention of the deprivation payment is to compensate for presumed extra workload. We criticise the use of the Jarman index in this context.

Allocation by formula should be justified in terms of policy objectives, be based on good empirical evidence, and be simple. The deprivation payment is, indeed, simple, but the basic Jarman index is unsound.

The fundamental point is that there is no empirical evidence to show that the deprivation payment reflects extra workload. It may even have the perverse effect of generating longer list sizes. The payment should instead discourage larger lists-for example, by adopting a sliding scale of payments - and encourage those who respond to the needs for primary care in their area-for example, by paying for improvements in service.

Data should therefore be collected in a form that will enable the effective evaluation of the deprivation payments in practice. This should among other things monitor changes in list size, consultation rates, access, and practice income. ${ }^{22}$

More research aimed at getting a better idea of what factors determine general practitioner workload is also important. A broader range of factors needs to be considered, including the availability of other health and social services. The measurement of workload must take into account not only the rate of consultations but also other factors such as duration of visits; numbers of extra visits, referrals, and prescriptions; and amount of stress. The aim should be to establish some common unit of workload that incorporates time, resource costs, and difficulty and could be used to compare workload between practices and over time.

To translate the results of this research into a payment policy that contains the appropriate incentives we need a greater understanding of what factors influence general practitioner behaviour, what strategy they are following, and how the changes introduced by the NHS review influence them. Only as a result of scientific and well validated research on the behaviour and workload of general practitioners can a system of incentives and payments be developed that promotes more equity in the provision of primary care.

We thank Sal McNeil and Vanessa Waby for producing several versions of this paper at high speed. We also acknowledge the helpful comments of Alan Maynard and the help with computing provided by Keith Humphreys. R C-H acknowledges the support of the Economic and Social Research Council while writing this paper.

1 Department of Health. National Health Service General Medical Services Statement of fees and allowances payable to general medical practitioners in

Klein R. The politics of the National Health Service. London: Longman, 1983.

3 Hobbs R. Deprivation payments. Medical Monitor 1990 March 23:23.

4 Gray P, Marinker M, Maynard A. The doctor, the patient, and their contract. Gray P, Marinker M, Ma

5 Jarman B, Bosanquet N, Rice P, Dollimore M, Leese B. Uptake of immunisation in district health authorities in England. $B M \mathcal{F} 1988 ; 296$ 1775-8

6 Innes J, Stoddard S. Formula allocation as a policy tool: politics and measurement. Planning Outlook 1988;31:95-102.

7 Secretaries of State for Social Services, Wales, Northern Ireland, and Scotland. Promoting better health. London: HMSO, 1987. (Cmnd 249. )

8 Wilkin D, Hodkin P, Metcalf D. Factors affecting workload: Is received wisdom true? In: The Medical Annual. Bristol: John Wright, 1986:185-96.

9 Jarman B. Identification of underprivileged areas. $B M 7$ 1983;286:1705-9.

10 Jarman B. Underprivileged areas. The Medical Annual. Bristol: John Wright, 1985:224-43.

11 Welsh Office. Welsh intercensal survey, 1986. London: HMSO, 1987.

12 Office of Population Censuses and Surveys. Census of the population 1981. London: HMSO, 1983.

13 Carr-Hill RA. Health status, resource allocation and socio-economic conditions. Interim report of health needs research study for Wolverhampton Borough Counci and District Health Authority. York: Centre for Health Economics, University of York, 1987.

14 Irving D, Rice P. Information for health services planning from the 1981 census. London: King's Fund, 1984. (Technical paper KFC 84/11.)

15 Jarman B. Underprivileged areas: validation and distribution of scores. $B M \mathcal{Y}$ 1984;289:1587-92.

16 Thurnhurst C. The analysis of small area statistics and planning for health Statistician 1985;34:93-106.

17 Delamothe T. Deprived area payments. BMF 1990;300:1609-10.

18 Leavey R, Wood J. Does the underprivileged area index work? $B M \mathcal{F}$ 1985;291:709-11.

19 Charlton J, Lakhani A. Is the Jarman underprivileged area score valid? $B M f$ 1985;290:1714-6.

20 Curtis S. Use of survey data and small area statistics to assess the link between individual morbidity and neighbourhood deprivation. $f$ Epidemio Community Health 1990;44:62-8.

21 Donaldson C, Gerard K. Paying general practitioners: shedding light on the review of health services. I R Coll Gen Pract 1989;39:114-7.

22 Krasnik A, Groenewegen P, Pederson PA, et al. Changing remuneration systems: effects on activity in general practice. BMF 1990;300:1698-701.

(Accepted 2 October 1990)
The life expectancy of a patient with Parkinson's disease has been reported as being doubled if dopaminergic drugs are used. If this is so how early should treatment be started and should it be before symptoms have become troublesome?

It is generally agreed that since levodopa was introduced the life expectancy of patients with Parkinson's disease has been increased by at least a half. The patient who presents with clinical features of the disease is already severely depleted of dopamine. The disease is progressive although the rate is variable and in the early stages of treatment this is masked.

Dopaminergic drugs are best regarded as a substitution treatment and probably do not influence the underlying disease. Improvement is most marked with hypokinesia and although tremor improves in about $20 \%$ of patients it is often resistant to levodopa. It is doubtful whether dopaminergic drugs are justified when symptoms are minimal. This position was adopted at first because of fears that the treatment might aggravate the disease but there are other considerations. After five years of treatment about half of a group of patients report a deterioration in response together with involuntary movements, hallucination, or confusion. After 10 years the majority are affected in this way.

It seems advisable to reserve levodopa for the patient who is handicapped. My personal impression is that the long term results are better if the dose is kept low rather than being pushed to the limit at an early stage. A few patients with Parkinson's disease continue for many years with little progression of the disease and others are less incapacitated when the drug has to be withdrawn than might be expected.-BRYAN ASHWORTH, consultant neurologist, Edinburgh

Lees AJ. Is L-dopa harmful? In: Warlow C, Garfield J, eds. Dilemmas in the management of the neurological patient. Edinburgh: Churchill Livingstone, 1984: 115-25.

Marsden CD. L-dopa or bromocriptine for Parkinson's disease; which, how much and when? In Warlow C, Garfield J, eds. More dilemmas in the management of neurological disease. Edinburgh: Churchill Livingstone, 1987:1-7. 